\title{
SOME CONSIDERATIONS ON SEEDRO (SOUTH EASTERN EUROPE DISASTER RELIEF OPERATIONS) CONCEPT
}

\author{
Ioan- Dan POPA \\ „Nicolae Bălcescu“ Land Forces Academy, Sibiu, Romania \\ paragon1971@gmail.com
}

\begin{abstract}
SEEDRO (South Eastern Europe Disaster Relief Operations) Concept was approved on $21^{\text {st }}$ October 2009 during SEDM Ministerial Meeting in Sofia and open the way for SEEBRIG to be engaged not only in PSOs (Peace Support Operations) but also in DROs (Disaster Relief Operations). In this paper, I present some considerations about the importance of this concept for SEEBRIG (South Eastern Europe Brigade), the main activities developed related to this concept and what should be the way ahead in the evolution SEEDRO Concept.
\end{abstract}

Keywords: SEEDRO, SEEBRIG, disasters; relief operations, engineer forces.

\section{Introduction}

Disasters are a regular part of a global life, whether caused by act of nature or acts of a man. These events become humanitarian emergencies when their effects impact on a society or population whose inherent resources are insufficient to absorb the impact and deal with event's consequences. In the last period of time, the global physical environment is in permanent changing and the consequence of this is the increasing likelihood of environmental failures (earthquakes, floods, droughts etc.).

Our region cannot be out of these environmental changes, throughout its history, Southeastern Europe has experienced multiple disasters that have caused significant loss of life, human suffering and property damage. Different actors become involved in different disaster responses, mainly acting as it is depicted in Figure 1. The role they play usually depends on a combination of factors: the nature of the disaster, the country's general approach on the use of military assets, the location of the disaster site, and national interests and the particular diplomatic and historical relations with the affected country.

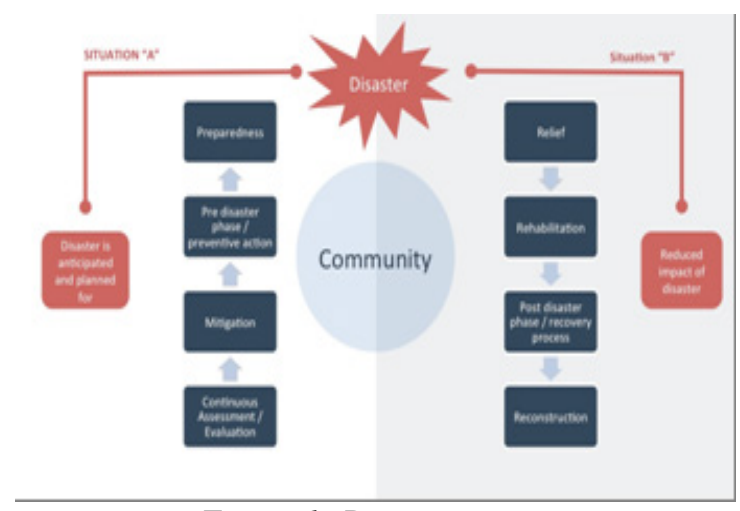

Figure 1: Disaster management

SEEBRIG (South Eastern Europe Brigade) was established by the MPFSEE Nations to contribute to peace and stability in Southeastern Europe. With $2^{\text {nd }}$ Additional Protocol, Nations established an Engineer Task Force (ETF). ETF's aim was to provide the Parties with a Rapid Relief and Humanitarian intervention capabilities. This initiative is to be oriented towards small-scale civil assistance in the interest of the Parties. 


\section{Considerations on SEEDRO (South Eastern Europe Disaster Relief Operations) Concept}

Considering the evolving number of disasters in South Eastern Europe, SEEBRIG nations have started to develop SEEDRO (South Eastern Europe Disaster Relief Operations) Concept. The first ideas about this concept were raised during CMEP-Civil Military Emergency Planning Seminar held in Plovdiv, during the period 15-19 February 2003. SEEBRIG representatives participated in this meeting and presented the possible role of the Brigade in Disaster Relief Operations. Immediately after, acording to the decision of the $9^{\text {th }}$ PMSC Meeting held in Sinaia, on 12-13 March 2003, a SEDROWGM-SEDRO Working Group Meeting was established to develop TORTerms of Reference and Concept, based on existing ETF-Engineer Task Force structure and capabilities. In this respect, it was issued the $1^{\text {st }}$ draft of SEEDRO Concept dated 09 May 2003 in order to be discussed during $1^{\text {st }}$ SEDROWGM in Plovdiv, in the period 26-30 May 2003. After this meeting it was issued the second $2^{\text {nd }}$ draft of SEEDRO Concept dated 30 May 2003.

After PMSC-Politico Military Steering Committee guidance and Nations comments, SEEBRIG prepared $3^{\text {rd }} \mathrm{draft}$ of SEEDRO Concept dated 23 January 2004, which was discussed in the next SEDROWGM held in Constanţa, from 1013 February 2004.

After considering again the Nation's comments and proposals the $4^{\text {th }}$ draft of SEEDRO Concept dated 18 April 2005 was issued.

After all these steps, the process was postponed because SEEBRIG focused all resources in getting FOC-Full Operational Capability for mission in Afghanistan.

Eventually, as a result of HLEM-High Level Expert Meeting held in Istanbul, during the period 23-26 February 2009, it was issued the $5^{\text {th }}$ draft of SEEDRO
Concept dated 26 February 2009. This version was proposed for approval during $22^{\text {nd }}$ PMSC Meeting and was approved on $21^{\text {st }} \quad$ October 2009 during SEDM Ministerial Meeting in Sofia.

As it has already noticed, it was not an easy process to obtain the final approved document of SEEDRO Concept (it took almost 6 years) but it was very important because this was the starting point for future developing of all related documents concerning DROs (GDPGeneric Deployment Plan, GOP-Generic Operational Plan, SOPs and Contingency Plans for DROs).

Previous planning for SEEBRIG, operations did not include disaster relief. The current force structure of ETF is organized for small-scale civil assistance like:

$\checkmark$ Limited road construction and repair;

$\checkmark$ Limited bridging;

$\checkmark$ Limited rail repair;

$\checkmark$ Earth moving;

$\checkmark$ Drainage;

$\checkmark$ Limited de-mining;

$\checkmark$ Unexploded Ordnance clearance;

$\checkmark$ Any other agreed functional areas within capabilities.

The Crisis Engineer Cell (CEC), once activated, will coordinate all Engineer Task Force (ETF) actions.

In order to be effective, the concept was based on the following assumptions:

$\checkmark$ A nation affected by a disaster or a relevant International Organization (e.g. UN, NATO, EU etc) requests SEEBRIG's assistance; $\checkmark$ The PMSC tasks COMSEEBRIG to provide assistance with ETF to the affected nation in accordance with the Concept;

$\checkmark$ SEEBRIG is not already involved in PSO or DRO, when the disaster occurs;

$\checkmark$ The financial burden of assistance provision is approved by 
the MPFSEE nations, and sufficient funds are allocated in the HQ SEEBRIG yearly budget;

$\checkmark \mathrm{HN}$ at permanent HQ location fulfills all the necessary requirements described in the Concept.

All the intervention process will be occurred in three phases, as follows:

$\checkmark$ Phase 1: Crises Engineer Cell (CEC) activation;

$\checkmark$ Phase 2: Engineer Task Force (ETF) involvement;

$\checkmark$ Phase 3: Redeployment of Crises Engineer Cell (CEC) and Engineer Task Force (ETF)

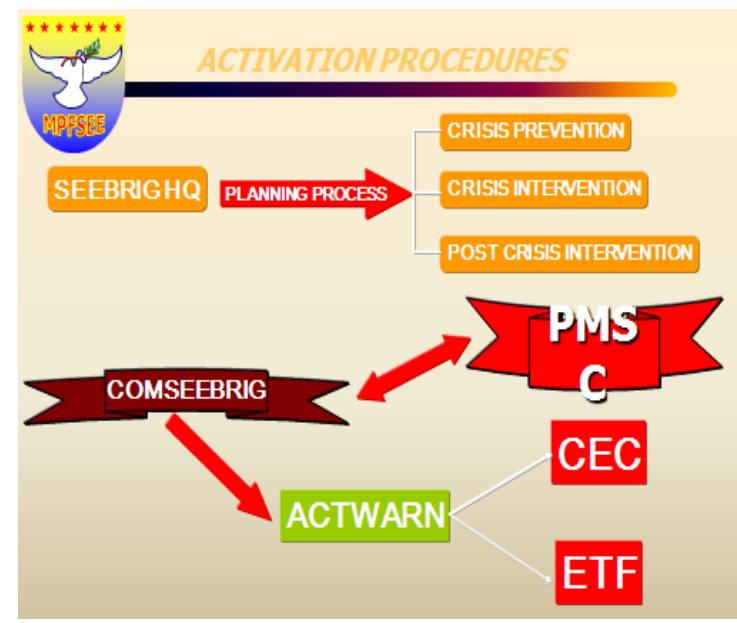

Figure 2: Activation process

In accordance with the approved version of SEEDRO Concept, for any DRO mission, an ad-hoc task force will be constituted with the following core assets: SEEBRIG Nucleus Staff,

SEEBRIG HQ Coy, SEEBRIG Signal Coy and ETF-Engineer Task Force. The need for other units with specific capabilities depending on the DRO needs, skilled personnel, special equipment (both provided by MPFSEE-Multinational Peace Force South Eastern Europe or third parties) and SEEBRIG Contingency Establishment Personnel (if needed) will be determined at the Force Generation Conference and after the FPLT - Forward Planning and Liaison Team reconnaissance.

An important instrument of certifying the validity of SEEDRO Concept was SEESIM (Southeastern Europe Simulation) series of Computer Assisted Exercises (CAX) within the framework of the South Eastern Europe Defense Ministerial (SEDM) process. In this kind of exercises, SEEBRIG usually acting as a response cell or as an interface between nations and other actors which are involved in the exercise (GOs, NGOs etc.), the main objectives for this exercises being as follows:

$\checkmark$ To exercise and improve SEEBRIG HQ Command and Control in DROs (Disaster Relief Operations);

$\checkmark$ To enhance cooperation and coordination with civil-emergency organizations, national and international;

$\checkmark$ To review and revise all SEEBRIG documents related to DROs;

$\checkmark$ To identify and exercise rapid procedures for involvement in emergency situations;

$\checkmark$ To train SEEBRIG HQ Nucleus Staff personnel to react in emergency situations.

SEESIM is an excellent opportunity for SEEBRIG HQ to review and revise all the documents related to DROs and to enhance cooperation and coordination with civil-emergency organizations, national and international.

At the same time, this kind of exercises give to SEEBRIG HQ the chance to be familiarized with the proper channels of communication with other Emergency Operation Centers - EOCs, national authorities as well as with various international organizations and to gain significant knowledge and enhanced their own abilities and expertise in DROs.

\section{Conclusions}

There is a real need of actualization of some aspects of SEEDRO Concept and during this process should be clarified all 
aspects related to possible discrepancies between MPFSEE Agreement and SEEDRO Concept, to consider the shortening of decision making process and preparation phase (Rapid Response is vital for DROs), the readiness status of the units which will be involve in DROs (need of high readiness units in order to be engage in the early stages of disasters), the financial aspects (would be ideal to have some money in the budget designated in advance, only for DROs) and the need to reinforce the units with specialized personnel and equipment (SAR-Search and Rescue Teams, MMT-Mobile Medical Teams etc).

As a conclusion, if we want to have SEEBRIG involved in real DROs missions in our region, for the benefit of our countries, we need a strong determination from our nations to develop SEEDRO Concept, otherwise this project will remain only a paper in SEEBRIG archive.

[1] www.seebrig.org;

\section{References}

[2] Doctrine of engineer forces in joint operations, Edition 2016;

[3] I.D. Popa, SEEDRO Concept-Quo Vadis?, Stars Informers-South Eastern Europe Brigade Review, July 2011, Issue III, page 21 